\title{
Avaliação de impacto à saúde da incidência de dengue associada à pluviosidade no município de Ribeirão Preto, São Paulo
}

\author{
Health impact assessment of the incidence of dengue \\ associated with precipitation in the city of Ribeirão Preto, São Paulo
}

\author{
Ana Flávia Barbosa Gabriel'1, Karina Camasmie Abe ${ }^{1}$, Marcelo de Paiva Guimarães 2,3 , \\ Simone Georges El Khouri Miraglia ${ }^{1}$
}

\begin{abstract}
Resumo
Introdução: A dengue é considerada um problema de saúde pública. O município de Ribeirão Preto possui condições climáticas e geográficas favoráveis à proliferação do Aedes aegypti, sendo reportadas altas taxas de incidência de dengue. Objetivo: Avaliar a relação entre a precipitação pluviométrica e a incidência de casos confirmados de dengue. Método: Foi utilizado o coeficiente de correlação de Spearman para a análise da relação entre a pluviosidade e a incidência de dengue. Resultados: Encontrou-se associação entre a precipitação e os casos de dengue, com $p<0,01$, considerando um intervalo de defasagem (time lag) que ocorre a partir do primeiro mês e se estende até o quinto mês. Conclusão: Estudos como este contribuem para o conhecimento sobre a influência de fatores climáticos na incidência e na dinâmica de transmissão da dengue, sendo essenciais para auxiliar os gestores na tomada de decisão para a prevenção e o controle da doença.
\end{abstract}

Palavras-chave: fatores climáticos; aedes aegypti; epidemiologia; precipitação pluviométrica.

\begin{abstract}
Background: Dengue is considered a public health problem. The municipality of Ribeirão Preto has climatic and geographical conditions conducive to the proliferation of Aedes aegypti and high rates of dengue incidence are reported. Objective: To evaluate the relationship between rainfall and the incidence of confirmed cases of dengue. Method: The Spearman Correlation Coefficient was used to analyze the relationship between rainfall and the dengue incidence. Results: An association between precipitation and dengue cases was found, with $p<0.01$, considering a time lag, which occurs from the first month until the fifth month. Conclusion: Studies such as this contribute to the knowledge about the influence of climatic factors on the incidence and transmission dynamics of dengue fever, being essential to guide managers in decision making for disease prevention and control. Keywords: climatic factors; aedes aegypti; epidemiology; precipitation.
\end{abstract}

\footnotetext{
'Laboratório de Economia, Saúde e Poluição Ambiental, Instituto de Ciências Ambientais, Químicas e Farmacêuticas, Universidade Federal de São Paulo (UNIFESP) - Diadema (SP), Brasil.

Universidade Aberta do Brasil, Universidade Federal de São Paulo (UNIFESP) - São Paulo (SP), Brasil.

${ }^{3}$ Faculdade Campo Limpo Paulista (FACCAMP) - Campo Limpo Paulista (SP), Brasil.

Trabalho realizado no Instituto de Ciências Ambientais, Químicas e Farmacêuticas, Universidade Federal de São Paulo (UNIFESP) - Diadema (SP), Brasil. Endereço para correspondência: Simone Georges El Khouri Miraglia - Departamento de Engenharia Química, Instituto de Ciências Ambientais, Químicas e Farmacêuticas, Universidade Federal de São Paulo (UNIFESP), Rua São Nicolau, 210, $4^{\circ}$ andar - Centro - CEP: 09913-030 - Diadema (SP), Brasil E-mail: miraglia@terra.com.br

Fonte de financiamento: 0 presente trabalho foi realizado com apoio da Coordenação de Aperfeiçoamento de Pessoal de Nível Superior - Brasil (CAPES) - Código de Finaciamento 001- Número do processo: 1655386.

Conflito de interesses: nada a declarar. 


\section{INTRODUÇÃO}

A dengue é um dos principais problemas de saúde pública no mundo e considerada em expansão pela Organização Mundial da Saúde (OMS). Nos últimos 50 anos, a doença aumentou sua incidência em 30 vezes, ocasionando, anualmente, cerca de 50-100 milhões de infecções em mais de 100 países endêmicos ${ }^{1}$.

A dengue é uma doença infecciosa aguda febril, cujo agente etiológico apresenta quatro sorotipos (DENV-1, DENV-2, DENV-3 e DENV-4), os quais se manifestam de diversas formas e intensidades ${ }^{2}$. Assim, devido ao seu amplo espectro clínico, encontram-se dificuldades em diagnosticar a doença, confundindo-a com outras doenças que causam febre ${ }^{3}$. A dengue é transmitida por mosquitos de gênero Aedes, sendo a principal espécie o Aedes aegypti (A. aegypti) ${ }^{4}$ o qual também é o transmissor do vírus da febre amarela, do vírus chikungunya e do vírus zika, que causam doenças com altos potenciais de perdas sociais e econômicas ${ }^{5,6}$.

As doenças infecciosas transmitidas por vetores, como a dengue, poderão se agravar devido às consequências das mudanças climáticas, pois são influenciadas por variáveis, como temperatura, umidade relativa do ar, precipitação, entre outras. A pluviosidade é um fator importante para o surgimento de potenciais criadouros, para a sobrevivência e para a reprodução do A. aegypti ${ }^{7}$. Nos últimos anos, a busca de relações entre variáveis climáticas e incidência de dengue tem sido investigada por diversos pesquisadores ${ }^{8-14}$.

No Estado de São Paulo, o primeiro surto de dengue ocorreu em 1987 nos municípios de Guararapes e Araçatuba ${ }^{15}$. O município de Ribeirão Preto, situado no interior de São Paulo, passou por uma epidemia em 1990, com taxa de incidência de quase 547 casos por 100 mil habitantes ${ }^{16}$. Durante os anos seguintes, os índices mantiveram-se baixos; contudo, a partir de 2006, a incidência mostrou-se crescente. Em 2010, o coeficiente de incidência foi de 4.900 casos por 100 mil habitantes. Já em 2012, a taxa de incidência foi de 51 casos por 100 mil habitantes. Em 2016, a dengue alcançou seu auge, com a taxa de 5.196 casos por $100 \mathrm{mil}$ habitantes, além de 8 óbitos por essa doença ${ }^{17}$.

Nesse sentido, avaliar os fatores que contribuem para o aumento de dengue é de extrema importância para o controle dessa doença. Sendo assim, o presente estudo teve por objetivo avaliar a relação entre a precipitação pluviométrica e a ocorrência de casos confirmados de dengue em Ribeirão Preto no período de 2000 a 2016, visto que, até o presente momento, essa relação não foi estabelecida nesse local na série temporal em questão. Adicionalmente, visa-se dar auxílio aos gestores de saúde na escolha de medidas complementares de prevenção e de controle do vetor, a fim de amenizar a doença e seus impactos no município de estudo.

\section{MÉTODO}

Ribeirão Preto é um município do interior de São Paulo, região Sudeste do país, com latitude sul de $21^{\circ} 10^{\prime}$ e longitude oeste de $47^{\circ} 50^{\prime}$, distando cerca de $313 \mathrm{~km}$ a nordeste da capital. Ocupa uma área de aproximadamente $651 \mathrm{~km}^{2}$, dos quais $127 \mathrm{~km}^{2}$ estão em perímetro urbano. Segundo a classificação climática de Köeppen, o município possui o tipo Aw, que caracteriza regiões com clima tropical, apresentando estação chuvosa no verão e estação seca no inverno. Sua população foi estimada pelo Instituto Brasileiro de Geografia e Estatística (IBGE) ${ }^{18} \mathrm{em}$ 674.405 habitantes no ano de 2016, e sua economia é baseada em agronegócios, principalmente no setor sucroalcooleiro e na citricultura.

Os casos de dengue mensais, para o período de 2000 a 2016 , foram obtidos por meio do banco de dados do Sistema de Informação de Agravos de Notificação (Sinan Net) disponibilizado pelo site da prefeitura do município de Ribeirão Preto ${ }^{17,19}$. Para os dados de precipitação pluviométrica total e mensal, utilizou-se a base de dados do Centro Integrado de Informações Agrometeorológicas (CIIAGRO) ${ }^{20}$ para o mesmo período. As informações populacionais foram obtidas por meio da base de dados do $\mathrm{IBGE}^{18}$.

A estatística descritiva foi realizada por meio da criação de um banco de dados no programa Microsoft $\operatorname{Excel}^{\odot}$ (2010). Para o cálculo da taxa anual de casos de dengue, utilizou-se a razão entre o número de casos de dengue e a população respectiva de cada ano do período de estudo multiplicada por 100 mil habitantes.

Para a análise da associação da precipitação pluviométrica com os casos de dengue, foi utilizado o coeficiente de correlação de Spearman, cuja variação é de -1 a 1 . Utilizou-se a seguinte classificação do coeficiente de correlação: 0,00 a 0,25 = muito baixa; 0,26 a $0,49=$ baixa; 0,50 a $0,69=$ moderada; 0,70 a $0,89=$ alta; 0,90 a $1,00=$ muito alta ${ }^{21}$.

O procedimento clássico de correlação entre dengue e variáveis climáticas, geralmente, fornece correlações fracas, embora estatisticamente significantes ${ }^{22}$. Assim, tendo em vista o ciclo de vida do vetor e o período de incubação, considerou-se uma defasagem em um intervalo de tempo (time lag). Essa abordagem permite investigar os fenômenos resultantes das interações com o ambiente em determinado espaço de tempo ${ }^{22}$. Neste estudo, foi realizada a análise das variáveis, com defasagens entre 0 e 5 meses $(\operatorname{lag} 0$ - lag 5$)$. Os resultados foram obtidos pelo software SPSS Statistics (versão 21, IBM), e a correlação foi considerada estatisticamente significante para $p<0,01$.

Esta pesquisa foi aprovada pelo Comitê de Ética em Pesquisa da UNIFESP/HSP por meio do Parecer Consubstanciado no 3696290616, de 9 de julho de 2016. 


\section{RESULTADOS}

A incidência de dengue no município de Ribeirão Preto seguiu o padrão cíclico observado no Brasil, na região Sudeste e no Estado de São Paulo, intercalando períodos de surtos com períodos de latência (Figura 1).

Nota-se, na Figura 1, que a incidência de dengue no Brasil aumentou abruptamente em 2014, atingindo seu ponto máximo em 2015, com taxa de incidência de 8.260 casos por $100 \mathrm{mil}$ habitantes. Além disso, observa-se que Ribeirão Preto apresentou taxas superiores às taxas estadual, regional e nacional durante vários anos do período de estudo, com destaque para o período de 2009 a 2011 e o ano de 2013, quando houve a introdução do DENV-4 no município ${ }^{23}$. Além disso, a menor taxa de incidência observada foi de 9 casos por 100 mil habitantes, e a maior taxa, de 5.196,1 casos por 100 mil habitantes em 2016.

A Figura 2 mostra a precipitação anual e mensal, bem como os casos de dengue mensal em Ribeirão Preto no período de 2000 a 2016.

A caracterização pluviométrica anual, em Ribeirão Preto, segue um padrão comportamental que demonstra não haver tendências significativas em relação ao aumento ou à diminuição das chuvas da série investigada (Figura 2A). Não foi observado nenhum fenômeno climático ou período de pluviosidade anormal, ou seja, não condizente com a média esperada para o período. Como pode ser observado com o detalhamento mensal (Figura $2 \mathrm{~B}$ ), verifica-se que o período chuvoso é superior entre os meses de outubro a março, representando mais de $80 \%$ do volume total anual, comparado aos meses de abril a setembro, o que é esperado para o clima tropical, típico da região. Esse período de alta pluviosidade antecede o mês de abril, o qual, geralmente, apresenta o maior número de casos de dengue, como mostrado na Figura 2C, sugerindo uma possível associação em análises de tempo com defasagem.

Dessa forma, para verificar a correlação entre casos de dengue e precipitação pluviométrica mensal, utilizou-se o coeficiente de correlação de Spearman, cujos resultados se encontram na Tabela 1.

Pode-se verificar na Tabela 1 que não foi observada correlação entre o número de casos de dengue e a precipitação para o mesmo mês de análise $(\operatorname{lag} 0)$. A correlação foi significativa, com $\mathrm{p}<0,01$, quando se considerou que a chuva de determinado mês influenciou o número de casos de dengue de um mês até cinco meses após a sua ocorrência $(\log 1-\operatorname{lag} 5)$. No entanto, de acordo com a classificação de correlação, apenas o $\operatorname{lag} 2$ e o $\operatorname{lag} 3$ apresentaram correlação moderada.

A título de ilustrar a influência da precipitação na ocorrência de casos de dengue para um período de tempo isolado, considerando o $\log 2$ e o $\operatorname{lag} 3$, elaborou-se a Figura 3, que representa a relação

Tabela 1. Correlação de Spearman entre casos de dengue e precipitação, considerando time lag nos anos de 2000 e 2016

\begin{tabular}{cc} 
Time Lag & $\begin{array}{c}\text { Casos de dengue } \times \\
\text { Precipitação }\end{array}$ \\
$\operatorname{Lag} 0$ & 0,034 \\
$\operatorname{Lag} 1$ & $0,301^{\star}$ \\
$\operatorname{Lag} 2$ & $0,513^{\star}$ \\
$\operatorname{Lag} 3$ & $0,581^{\star}$ \\
$\operatorname{Lag} 4$ & $0,479^{*}$ \\
$\operatorname{Lag} 5$ & $0,256^{*}$ \\
\hline
\end{tabular}

${ }^{*} \mathrm{p}<0,01$

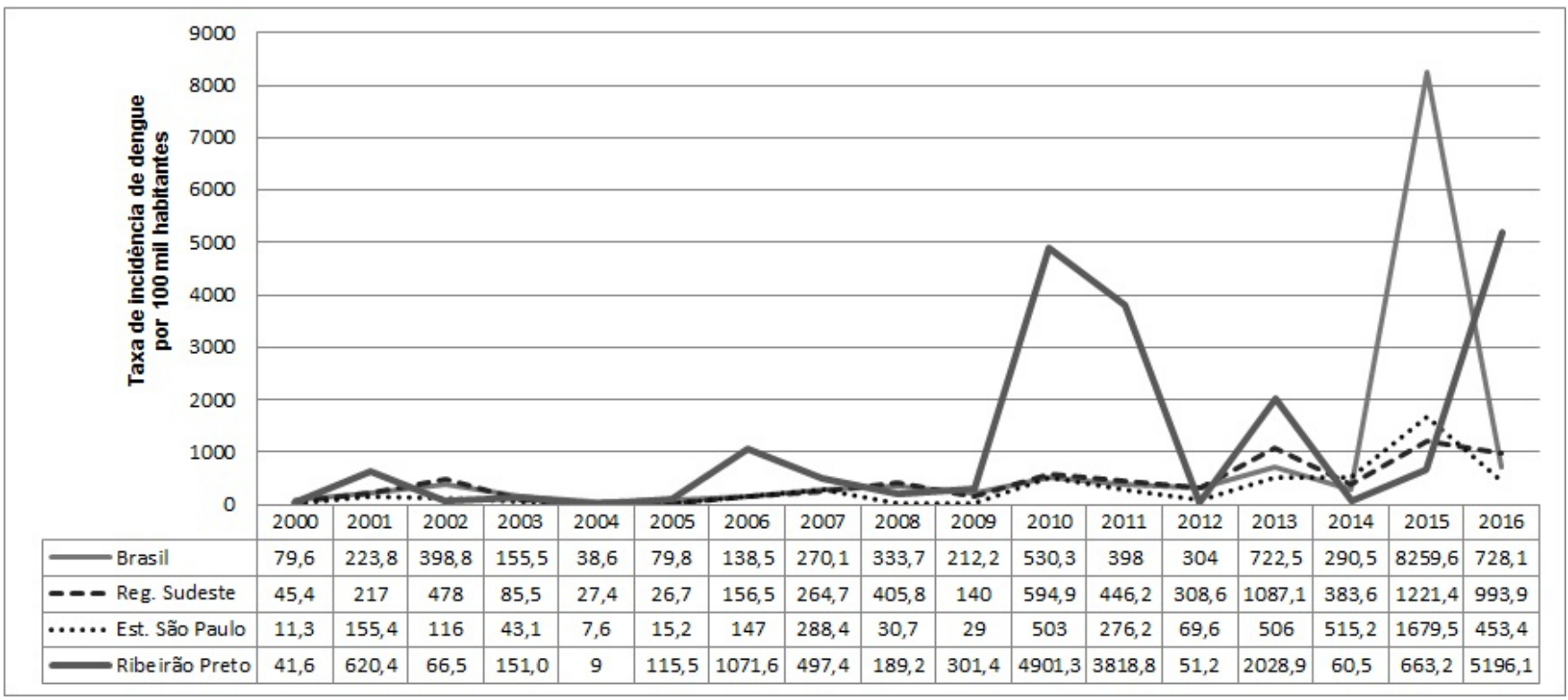

Figura 1. Taxa de incidência de casos de dengue por 100 mil habitantes no Brasil, na região Sudeste, no Estado de São Paulo e em Ribeirão Preto, no período de 2000 a 2016, segundo dados do SINAN-Net e IBGE 

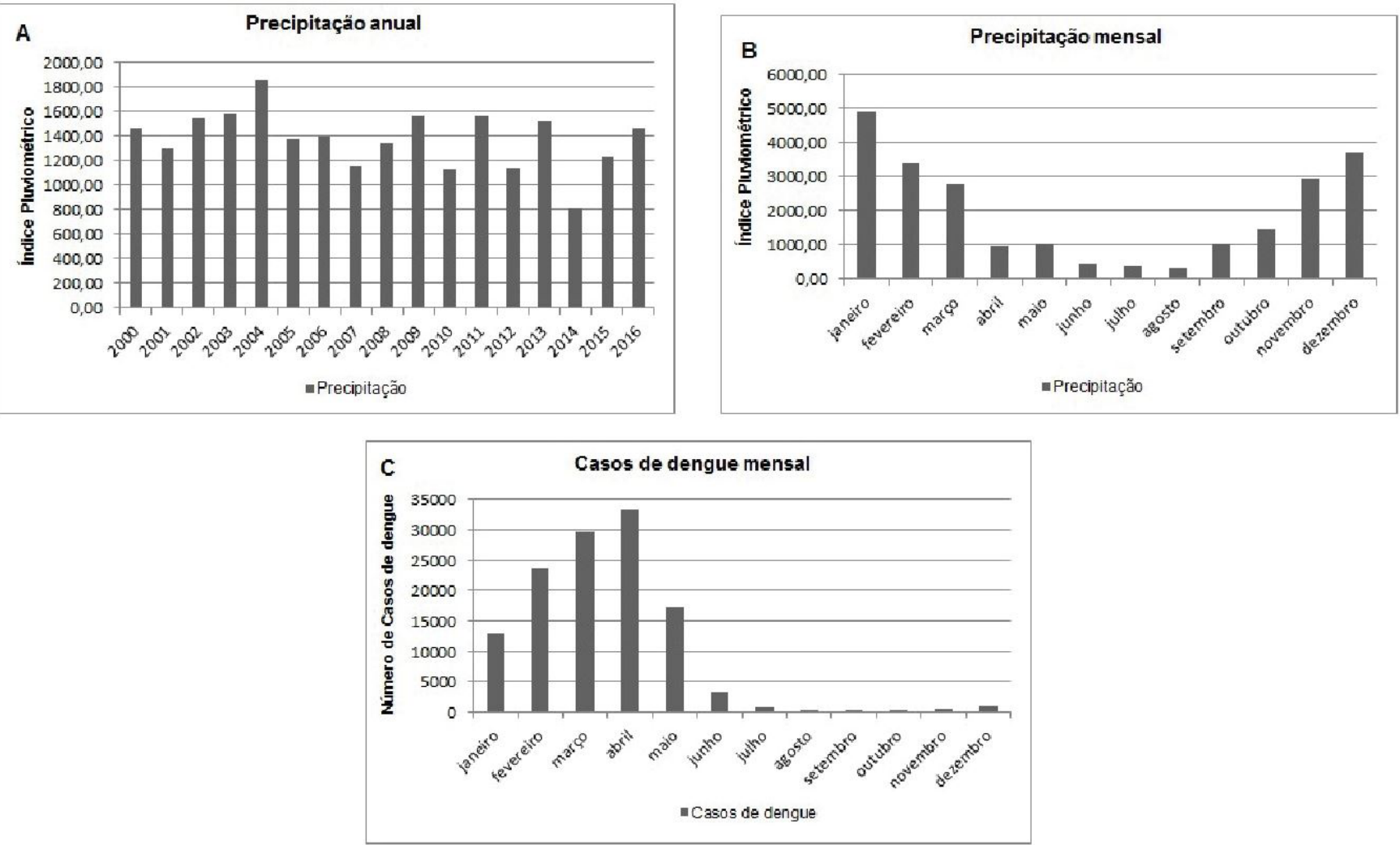

Figura 2. (A) Precipitação pluviométrica anual; (B) Precipitação pluviométrica mensal; (C) casos de dengue mensal do município de Ribeirão Preto, considerando o período de 2000 a 2016, com base nos dados do SINAN-Net e CIIAGRO

A

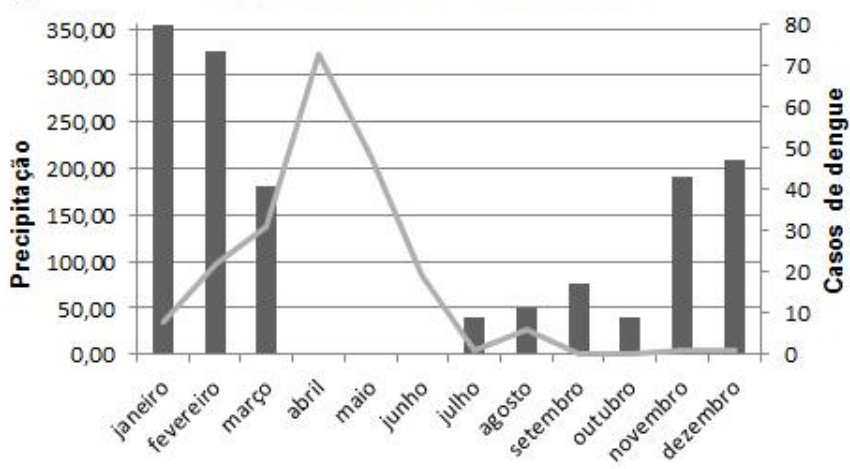

B

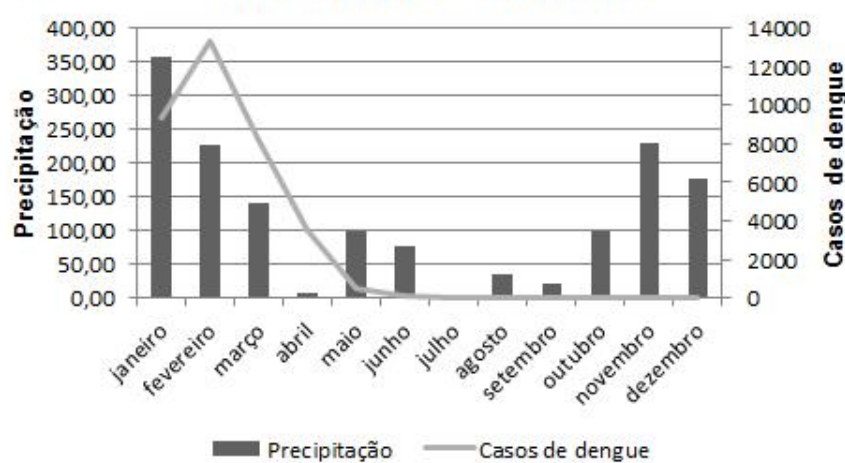

Precipitação X Casos de dengue (lag 3)

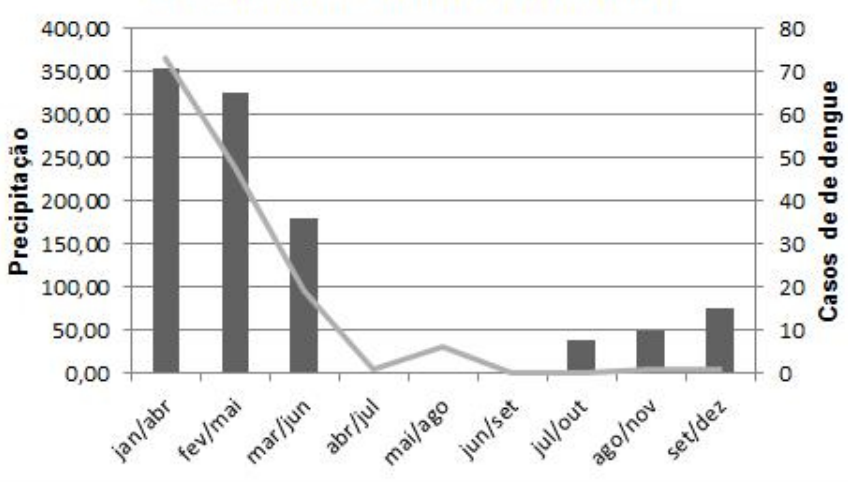

Precipitação X Casos de dengue (lag 2)

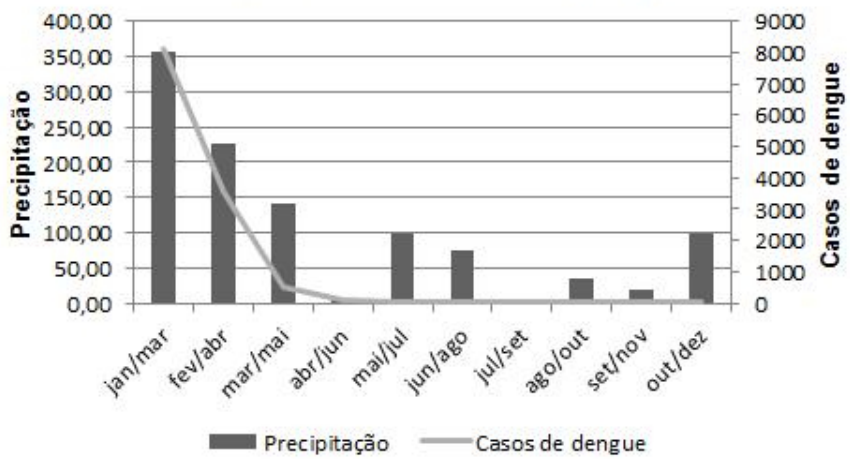

Figura 3. Relação entre precipitação pluviométrica e casos de dengue, considerando time lag nos anos de (A) 2000 e de (B) 2016, com base nos dados do SINAN-Net e CIIAGRO 
entre as variáveis para os anos de 2000 e 2016, representativos do início e do final do período analisado.

Nos anos de 2000 e 2016, janeiro foi o mês com maior pluviosidade; dessa forma, a correlação de Spearman sugere que a chuva desse mês contribuiu para o aumento significativo do número de casos nos meses de fevereiro, março, abril, maio e junho.

A influência da chuva na geração de casos de dengue pode variar a cada ano; assim, no ano de 2000, o maior coeficiente de correlação foi o de lag 3. Assim, a precipitação de janeiro favoreceu a proliferação do vetor e, consequentemente, o aumento de casos, atingindo o ápice em abril (Figura 3A). Em 2016, o número de casos de dengue do mês de março foi o mais influenciado pelas chuvas do mês de janeiro, como é possível observar na Figura 3B, visto que o maior coeficiente de correlação de Spearman foi o de lag 2. Analogamente, essa análise pode se estender para qualquer mês e ano.

Além de analisar a associação da precipitação com os casos de dengue, pode-se avaliar a distribuição do número de casos nas estações do ano. Em Ribeirão Preto, o número de casos de dengue por estação do ano, considerando o período estudado, foi de 66.233 casos no verão, 53.754 no outono, 1.316 no inverno e 1.775 na primavera. As estações do verão e do outono apresentaram o maior número de casos de dengue, com 53,8 e 43,7\%, respectivamente. Já as estações do inverno e da primavera possuem índices baixos, com 1 e 1,4\% do total de casos, respectivamente.

\section{DISCUSSÃO}

A partir de 2014, houve um rápido crescimento na incidência de casos de dengue no Brasil, atingindo seu ápice em 2015. Nesse mesmo período, ocorreu a crise hídrica no país, afetando, principalmente, a região Sudeste ${ }^{24}$. Dessa forma, a população passou a improvisar métodos para o armazenamento de água ${ }^{25}$. A presença abundante de reservatórios improvisados pode ter favorecido a proliferação do $A$. aegypti e, consequentemente, o aumento dos casos de dengue. Além disso, em 2015, ocorreram os primeiros registros de casos de febre pelo vírus zika no país, culminando em mais de 2.400 casos e 29 óbitos distribuídos em 549 municípios brasileiros, além de aproximadamente $18 \mathrm{mil}$ casos confirmados de febre de chikungunya ${ }^{26-28}$.

Em Ribeirão Preto, durante o período de 2000 a 2016, foram confirmados 123.078 casos de dengue, representando 6\% dos casos registrados no Estado de São Paulo. O quadro registrado demonstra o paradoxo de uma cidade que, apesar de abrigar um dos maiores centros de excelência médica do país e possuir outros bons indicadores sociais, como saneamento e educação, ainda apresenta alta incidência de dengue, ressaltando a necessidade da população em adquirir os hábitos de combate ao vetor ${ }^{29}$. Ademais, segundo Chiaravalloti Neto et al. ${ }^{30}$, existe um maior risco de transmissão de dengue em áreas com maior densidade demográfica. Sendo assim, faz-se necessário ressaltar que Ribeirão Preto é um dos municípios mais populosos ${ }^{31}$, com densidade demográfica de 1.036,1 hab $/ \mathrm{km}^{2}$ em 2016, situando-se acima da densidade demográfica estadual, que foi de $180,3 \mathrm{hab} / \mathrm{km}^{2}$. Portanto, nota-se que o município possui condições geográficas favoráveis para a transmissão do DENV. Outro fator que contribui para a alta incidência de dengue da cidade são as condições climáticas, cujo índice médio de precipitação pluviométrica total anual é de $1.380 \mathrm{~mm}$, com temperatura máxima variando entre 26 e $30{ }^{\circ} \mathrm{C}$, sendo que a temperatura ideal para o desenvolvimento das larvas varia entre 25 e $30^{\circ} \mathrm{C}^{32}$. Ribeiro et al. ${ }^{8}$ destacam que a pluviosidade, além de aumentar os locais para o desenvolvimento das formas imaturas do vetor, gera condições ambientais favoráveis para o desenvolvimento de vetores adultos. Como prováveis lugares de reprodução cheios de água das chuvas, há as garrafas e os pneus de carro descartados, os buracos de árvores, os pratos de planta e outros recipientes ${ }^{33}$.

No presente estudo, a correlação entre o número de casos de dengue e a precipitação pluviométrica não foi observada para o mesmo mês de análise $(\log 0)$. Dessa forma, considerando que o vetor da dengue leva de 8 a 10 dias para completar seu ciclo (ovo, larva, pupa e adulto) e sobrevive, em média, 30 dias, torna-se necessário considerar o conceito de time lag $g^{34}$. A correlação entre as variáveis com o time lag foi significativa estatisticamente a partir do lag 1 e se estendeu até o lag 5, isto é, a precipitação de determinado mês contribuiu para explicar o número de casos de dengue de um mês até cinco meses após a sua ocorrência (Tabela 1). A correlação foi moderada para o $\operatorname{lag} 2$ e o $\operatorname{lag} 3$, ou seja, pode haver maior influência da precipitação nos casos de dengue com dois ou três meses de defasagem.

Além das características inerentes ao clima em relação à regularidade e à quantidade de chuvas, não foi observado nenhum fenômeno climático anormal que afetasse o regime de chuvas em Ribeirão Preto no período analisado. A precipitação apresentou variabilidade, sugerindo que a sua influência nos casos de dengue pode ser diferente a cada ano. Dessa forma, pode haver uma maior correlação para determinado ano com algum dos lag 1- lag 5 significativos, especialmente com lag 2 e lag 3, como demonstrado nos resultados.

Os resultados do presente artigo seguem a mesma tendência do estudo de Silva et al..$^{35}$, em que a pluviosidade foi associada ao número de casos de dengue com defasagem de três meses. Outros estudos também encontraram associação, com time lag, entre precipitação e casos de dengue. Segundo Brunkard et al. ${ }^{36}$, na fronteira dos Estados Unidos com o México, a correlação foi significativa duas semanas após cada aumento de $1 \mathrm{~cm}$ na precipitação semanal. Já na Tailândia, utilizou-se o coeficiente de correlação de Pearson para analisar a associação entre os casos 
de dengue e os fatores climáticos, com resultados fortemente correlacionados no mesmo mês de ocorrência; no entanto, com um mês de defasagem, apresentou-se maior correlação ${ }^{37}$. De acordo com Chen et al. ${ }^{38}$, eventos extremos de precipitação estão associados com a ocorrência de 8 doenças infecciosas com defasagens de 0 a 70 dias, sendo que, para dengue, o time lag é de 70 dias. Em Barbados, foi analisada correlação entre variáveis climáticas e casos de dengue, constando associação com a precipitação em um intervalo de 7 semanas ${ }^{22}$.

A incidência de dengue em Ribeirão Preto apresentou padrão sazonal com a maior ocorrência de casos nos cinco primeiros meses do ano, coincidindo com as estações do verão e do outono. As características dessas estações na cidade favoreceram para que elas apresentassem o maior número de casos de dengue. Da mesma maneira, o inverno foi marcado pela redução dos casos. Já a primavera é uma estação com aumento gradativo das chuvas e das temperaturas médias, contribuindo para potenciais focos do A. aegypti e influenciando a incidência de dengue no verão devido ao time lag apresentado anteriormente.

Vale ressaltar que as ações de prevenção e controle da dengue no Brasil não possuem caráter permanente, sendo retomadas e intensificadas na época do verão ${ }^{39}$. O Governo Federal, durante o verão, intensifica as iniciativas, que incluem campanhas publicitárias e educativas, mutirões de faxina, entre outras ${ }^{40}$. Uma estratégia satisfatória de controle dos transmissores dos mosquitos é a vigilância epidemiológica, pois aborda todos os determinantes envolvidos na dengue ${ }^{41}$. Além disso, sugere-se que as campanhas sejam contínuas em todas as estações do ano e intensificadas, principalmente, a partir da estação da primavera, no mês de setembro, quando há o aumento gradativo de chuvas, influenciando o crescimento de casos nos meses subsequentes.

A dinâmica de transmissão da dengue envolve vários determinantes; sendo assim, os resultados deste estudo podem ser adaptados a outras variáveis climáticas e/ou sociais e a outras regiões.

Os resultados encontrados mostraram a existência de associação entre os casos de dengue e a precipitação no município de Ribeirão Preto, identificando que a pluviosidade contribuiu de um a cinco meses na geração de novos casos de dengue. Vale ressaltar que esses resultados poderão auxiliar os gestores em saúde do munícipio de Ribeirão Preto na manutenção do controle da dengue, evitando possíveis surtos na cidade.

O padrão sazonal de incidência da doença coincide com as estações do verão e do outono devido à influência do aumento gradativo das chuvas na primavera e de suas características climáticas e geográficas, as quais são propícias para o desenvolvimento do A. aegypti.

Portanto, o conhecimento sobre a influência de fatores climáticos na incidência de dengue e a dinâmica de transmissão é essencial para a tomada de decisão em relação à problemática apresentada. Assim, recomenda-se aos gestores em saúde a utilização de inovações tecnológicas na elaboração de estratégias complementares, como a utilização de aplicativos e mapas com previsão de pontos epidêmicos, tornando mais eficiente o controle e a prevenção da dengue.

\section{REFERÊNCIAS}

1. World Health Organization. Dengue guidelines for diagnosis, treatment prevention and control [Internet]. Geneva: WHO; 2009 [citado em 2018 Mar. 23]. Disponível em http://apps.who.int/iris/bitstream/10665/44188/1/9789241547871_eng. pdf

2. Torres EM. Dengue. Estud Av. 2008;22(64):33-52. http://dx.doi.org/10.1590/ S0103-40142008000300004.

3. Murray NEA, Quam MB, Wilder-Smith A. Epidemiology of dengue: past, present and future prospects. Clin Epidemiol. 2013;5:299-309. PMid:23990732.

4. Braga IA, Valle D. Aedes aegypti: histórico do controle no Brasil. Epidemiol Serv Saude. 2007;16:113-8.

5. Vasconcelos PFC. Doença pelo vírus Zika: um novo problema emergente nas Américas? Pan-Amazônica Saude. 2015;6(2):9-10. http://dx.doi. org/10.5123/S2176-62232015000200001.

6. Fauci AS, Morens DM. Zika virus in the Americas - yet another arbovirus threat. N Engl J Med. 2016;374(7):601-4. http://dx.doi.org/10.1056/ NEJMp1600297. PMid:26761185.

7. Barbosa IR, Da Silva LP. Influência dos determinantes sociais e ambientais na distribuição espacial da dengue no município de Natal - RN. Rev Cien Plural. 2016;1(3):62-75.
8. Ribeiro AF, Marques GR, Voltolini JC, Condino ML. Associação entre incidência de dengue e variáveis climáticas. Rev Saude Publica. 2006;40(4):6716. http://dx.doi.org/10.1590/S0034-89102006000500017. PMid:17063244.

9. Lima EA, Firmino JLN, Gomes MF Fo. A relação da previsão da precipitação pluviométrica e casos de dengue nos estados de Alagoas e Paraíba nordeste do Brasil. Rev Bras Meteorol. 2008;23(3):264-9. http://dx.doi.org/10.1590/ S0102-77862008000300001.

10. Câmara FP, Gomes AF, Santos GT, Câmara DC. Clima e epidemias de dengue no Estado do Rio de Janeiro. Rev Soc Bras Med Trop. 2009;42(2):137-40. http://dx.doi.org/10.1590/S0037-86822009000200008. PMid:19448929.

11. Gomes AF, Nobre AA, Cruz OG. Análise temporal da relação entre dengue e variáveis meteorológicas na cidade do Rio de Janeiro, Brasil, no período de 2001 a 2009. Cad Saude Publica. 2012;28(11):2189-97. http://dx.doi. org/10.1590/S0102-311X2012001100018. PMid:23147960.

12. Viana DV, Ignotti E. A ocorrência da dengue e variações meteorológicas no Brasil: revisão sistemática. Rev Bras Epidemiol. 2013;16(2):240-56. http:// dx.doi.org/10.1590/S1415-790X2013000200002. PMid:24141998.

13. Campbell-Lendrum D, Manga L, Bagayoko M, Sommerfeld J. Climate change and vector-borne diseases: what are the implications for public health research and policy? Philos Trans R Soc Lond B Biol Sci. 2015;370(1665):2052. http://dx.doi.org/10.1098/rstb.2013.0552. PMid:25688013. 
14. Butterworth MK, Morin CW, Comrie AC. An analysis of the potential impact of climate change on dengue transmission in the Southeastern United States. Environ Health Perspect. 2017;125(4):579-85. http://dx.doi. org/10.1289/EHP218. PMid:27713106.

15. Pontes RJS, Ruffino-Netto A. Dengue em localidade urbana da região sudeste do Brasil: aspectos epidemiológicos. Rev Saude Publica. 1994;28(3):218-27. http://dx.doi.org/10.1590/S0034-89101994000300010. PMid:7747082.

16. Pontes RJS, Ruffino-Netto A. Vigilância e busca ativa de casos suspeitos de dengue hemorrágico em Ribeirão Preto, São Paulo. Rev Panam Salud Publica. 1997;1(3):186-92. http://dx.doi.org/10.1590/S1020-49891997000300004. PMid:9162587.

17. Ribeirão Preto. Prefeitura Municipal. Boletim epidemiológico [Internet]. Ribeirão Preto: Secretaria de Saúde; 2018 [citado em 2018 Mar. 23]. Disponível em: http://www.ribeiraopreto.sp.gov.br/ssaude/pdf/dengue2014-casos.pdf

18. Instituto Brasileiro de Geografia e Estatística [Internet]. Rio de Janeiro: IBGE; 2018 [citado em 2018 Mar. 23]. Disponível em: http://www.ibge. com.br/cidadesat $/$ painel/populacao.php? codmun $=354340 \&$ search $=\% 7 \mathrm{C}$ \%7Cinfograficos:-evolucao-populacional-e-piramide-etaria\&lang

19. Ribeirão Preto. Prefeitura Municipal. Boletim epidemiológico [Internet]. Ribeirão Preto: Secretaria de Saúde; 2018 [citado em 2018 Mar. 23]. Disponível em: <https://www.ribeiraopreto.sp.gov.br/ssaude/pdf/boletim_dengue.pdf

20. Centro Integrado de Informações Agrometeorológicas [Internet]. São Paulo: CIIAGRO; 2018. Disponível em: http://www.ciiagro.sp.gov.br/ ciiagroonline/Quadros/QChuvaPeriodo.asp

21. Munro BH. Statistical methods for health care research. 5th ed. Philadelphia: Lippincott Williams \& Wilkins, 2005.

22. Depradine C, Lovell E. Climatological variables and the incidence of dengue fever in Barbados. Int J Environ Health Res. 2004;14(6):429-41. http://dx.doi.org/10.1080/09603120400012868. PMid:15545038.

23. Poloni TR, Dornas FP, Santos NN Jr, Soares AM, Amarilla AA, Alfonso HL, et al. High prevalence of clinically unsuspected dengue disease among children in Ribeirao Preto City, Brazil. J Med Virol. 2016;88(10):1711-9. http://dx.doi.org/10.1002/jmv.24533. PMid:27004990.

24. Marengo JA, Nobre CA, Seluchi ME, Cuartas A, Alves LM, Mendiondo EM, et al. A seca e a crise hídrica de 2014-2015 em São Paulo. Rev USP. 2015;106(106):31-44. http://dx.doi.org/10.11606/issn.2316-9036.v0i106p31-44.

25. Marcondes CB, Ximenes MF. Zika virus in Brazil and the danger of infestation by Aedes (Stegomyia) mosquitoes. Rev Soc Bras Med Trop. 2016;49(1):4-10 http://dx.doi.org/10.1590/0037-8682-0220-2015. PMid:26689277.

26. Organização Pan-Americana da Saúde. Zika vírus: microcefalia, sintomas e tratamentos [Internet]. OPAS; 2018. Disponível em: http://www.opas.org. br/zika-virus-microcefalia-sintomas-e-tratamentos/

27. Ministério da Saúde. Monitoramento dos casos de dengue e febre de chikungunya até a semana epidemiológica [Internet]. Brasília: Secretaria de Vigilância em Saúde; 2014. Disponível em: http://portalsaude.saude. gov.br/images/pdf/2015/janeiro/02/2014-039---Dengue-SE-47.pdf

28. Perry H, Khalil A, Aarons E, Russell K, O’Brien P. Management of Zika virus in pregnancy: a review. Br Med Bull. 2017;124(1):157-69. PMid:29253151.
29. Hino P, Villa TC, Cunha TN, Santos CB. Distribuição espacial de doenças endêmicas no município de Ribeirão Preto (SP). Cien Saude Colet. 2011;16(Suppl 1):1289-94. http://dx.doi.org/10.1590/S1413-81232011000700062. PMid:21503478.

30. Chiaravalloti F No. Descrição da colonização de Aedes aegypti na região de São José do Rio Preto, São Paulo. Rev Soc Bras Med Trop. 1997;30(4):27985. http://dx.doi.org/10.1590/S0037-86821997000400002. PMid:9265223.

31. Instituto Brasileiro de Geografia e Estatística [Internet]. Rio de Janeiro: IBGE; 2013 [citado em 2018 Mar. 23]. Disponível em: https://agenciadenoticias. ibge.gov.br/agencia-noticias/2013-agencia-de-noticias/releases/9497-ibgedivulga-as-estimativas-populacionais-dos-municipios-em-2016.html

32. Ajuz LC, Vestena LR. Influência da pluviosidade e temperatura ambiente na longevidade e fecundidade dos Aedes aegypti e albopictus na cidade de Guarapuava-PR e possibilidade de superinfestação. Hygeia Rev Bras Geogr Med Saude. 2014;10(18):1-18.

33. Cheong YL, Burkart K, Leitão PJ, Lakes T. Assessing weather effects on dengue disease in Malaysia. Int J Environ Res Public Health. 2013;10(12):6319-34. http://dx.doi.org/10.3390/ijerph10126319. PMid:24287855.

34. Weber AA, Wollmann CA. A influência climática na proliferação do mosquito Aedes aegypti em Santa Maria-RS, em 2012. Ciênc Nat. 2016;38(3):1246. http://dx.doi.org/10.5902/2179460X21386.

35. Silva FD, Santos AM, Corrêa RGCF, Caldas AJM. Temporal relationship between rainfall, temperature and occurence of dengue cases in São Luís, Maranhão, Brazil. Cien Saude Colet. 2016;21(2):641-6. http://dx.doi. org/10.1590/1413-81232015212.09592015. PMid:26910171.

36. Brunkard JM, Cifuentes E, Rothenberg SJ. Assessing the roles of temperature, precipitation, and ENSO in dengue reemergence on the Texas-Mexico border region. Salud Publica Mex. 2008;50(3):227-34. http://dx.doi.org/10.1590/ S0036-36342008000300006. PMid:18516370.

37. Jeefoo P, Tripathi NK, Souris M. Spatio-temporal diffusion pattern and hotspot detection of dengue in Chachoengsao province, Thailand. Int J Environ Res Public Health. 2011;8(1):51-74. http://dx.doi.org/10.3390/ ijerph8010051. PMid:21318014.

38. Chen MJ, Lin CY, Wu YT, Wu PC, Lung SC, Su HJ. Effects of extreme precipitation to the distribution of infectious diseases in Taiwan, 19942008. PLoS One. 2012;7(6):e34651. http://dx.doi.org/10.1371/journal. pone.0034651. PMid:22737206.

39. Lenzi MF, Coura LC. Prevenção da dengue: a informação em foco. Rev Soc Bras Med Trop. 2004;37(4):343-50. http://dx.doi.org/10.1590/S003786822004000400011. PMid:15334270.

40. Bogaz C. Combate ao aedes: saúde realiza primeira reunião com gestores de 2017 [Internet]. Brasília: Ministério da Saúde; 2017. Disponível em http://combateaedes.saude.gov.br/pt/noticias/903-combate-ao-aedessaude-realiza-primeira-reuniao-com-gestores-de-2017

41. Costa AR, Santana CM, Silva VL, Pinheiro JAF, Marques MMM, Ferreira PMP. Análise do controle vetorial da dengue no sertão piauiense entre 2007 e 2011. Cad Saude Colet. 2016;24(3):275-81. http://dx.doi.org/10.1590/1414$462 \times 201600030035$. 